\title{
PENGARUH PERUBAHAN ORGANISASI TERHADAP KINERJA PERUSAHAAN DAERAH AIR MINUM (PDAM) KOTA BANDUNG
}

\author{
Nina Karlina \\ Fakultas Ilmu Sosial Dan Ilmu Politik Universitas Padjadjaran \\ Jalan Bukit Dago Utara No. 25 Bandung 40135 \\ Email : karlina_nina@yahoo.com
}

\begin{abstract}
ABSTRAK. Kinerja PDAM Kota Bandung masih belum optimal, dimana saat ini air bersih yang sampai ke pelanggan masih belum memenuhi kualitas standar air minum. Belum lagi sejumlah persoalan yang secara umum melingkupi pengelolaan PDAM Kota Bandung. Penelitian ini dilakukan pada aspek struktur organisasi dan kinerja yang dicapai, sehingga menggunakan desain kuantitatif. Dengan desain ini, peneliti melakukan explanatory survey. Desain penelitian ini dilakukan dengan cara survei untuk mengumpulkan informasi dari responden dengan menggunakan angket. Populasi dalam penelitian ini adalah pihak-pihak yang terkait dengan hasil restrukturisasi organisasi PDAM dan secara langsung terkait pula dengan kinerja organisasi PDAM Kota Bandung. Teknik penentuan sampel dilakukan dengan cara proportionate stratified random sampling. Dalam penelitian ini teknik analisis data yang digunakan adalah Structural Equation Modeling (SEM) Hasil penelitian menunjukkan bahwa perubahan organisasi memiliki pengaruh yang signifikan terhadap kinerja PDAM Kota Bandung.
\end{abstract}

Kata kunci : Perubahan organisasi, Restrukturisasi, Kinerja organisasi, PDAM Kota Bandung, Penempatan pegawai.

\section{EFFECT ON PERFORMANCE OF ORGANIZATION CHANGES AT BANDUNG REGIONAL WATER SUPPLY (PDAM)}

ABSTRACT. The performance of PDAM Bandung City is still not optimal, where the current clean water until the customer has not met the quality standard of drinking water. Not to mention a number of issues which generally covers the management of PDAM Bandung. This research was conducted on aspects of organizational structure and performance are achieved, so that use quantitative design. With this design, researchers conducted a survey explanatory. The study design was done by a survey to collect information from respondents using a questionnaire. The population in this study are parties related to the organizational restructuring of PDAM and also directly associated with organizational performance PDAM Bandung City. Sampling technique was done by proportionate stratified random sampling. In this research, data analysis technique used is Structural Equation Modeling (SEM). The results showed that organizational change has a significant influence on the performance of PDAM Bandung City, where the 
contribution of this organizational change is affecting the performance of PDAM Bandung City.

Keywords: Perubahan organisasi, Restrukturisasi, Kinerja organisasi, PDAM Kota Bandung, Penempatan pegawai.

\section{PENDAHULUAN}

Permasalahan utama yang dihadapi oleh PDAM Kota bandung saat ini terletak pada 3 aspek, yaitu aspek teknis, aspek manajemen, dan aspek keuangan. Pada aspek teknis, permasalahan terletak pada beberapa hal antara lain tingkat kehilangan air tinggi $( \pm 50 \%)$, cakupan produksi masih terbatas, hanya mencapai $( \pm 65 \%)$, suplai distribusi air bersih yang masih menggunakan system gilir dan lain lain. Pada aspek manajemen permasalahan terletak pada beberapa regulasi terkait kelembagaan dan kepegawaian yang sudah terlalu lama dan tidak sesuai lagi dengan ketentuan ketentuan yang baru serta semangat otonomi daerah. Pada aspek keuangan masalah yang terjadi terkait dengan baban utang jangka panjang, piutang rekening air, tingginya reduksi terhadap pembayaran rekening, terbatasnya dan untuk investasi dan kinerja financial yang rendah (likuiditas, solvabilitas, rentabilitas). Melihat kondisi kinerja PDAM yang merosot maka PDAM melakukan perubahan organisasi di dalam perusahaan, yaitu dengan pertama tama merubah struktur organisasi PDAM.

Secara konseptual, perubahan organisasi dapat dijelaskan dari dua pendekatan, yaitu pendekatan dalam arti sempit dan dalam arti luas. Dalam arti sempit, perubahan organisasi secara sederhana dapat diberi pengertian sebagai perubahan dalam struktur organisasi atau upaya mendesain kembali struktur organisasi. Mintzberg (1979:65) mengartikan desain sebagai berikut:

In the case of organizational structure, design means turning those knows that influence the division of labor and the coordinating mechanism thereby affecting how the organizational functions- how materials authority, information and decision processes flow through it.

Perubahan dibedakan ke dalam dua konsep yaitu: perubahan yang direncanakan (planned change) dan perubahan yang tidak direncanakan (unplanned change) Winardi (2005:25). Perubahan yang tidak direncanakan terjadi secara spontan atau secara acak dan terjadi tanpa perhatian seorang agen perubahan, perubahan demikian dapat bersifat merusak (disruptif). Perubahan yang direncanakan merupakan sebuah reaksi langsung terhadap persepsi seseorang tentang adanya suatu celah kinerja 
Untuk variabel perubahan organisasi diukur oleh Jones (1995:232) yang mengemukakan bahwa : "Organizational change is the restructuring of resources and capabilities to increase the organizations ability to create value and improve the return to its stakeholders."

Jones (1995:481) : Organizational change typically involves the restructuring of : 1) Human resources, 2) Functional resources, 3) Technological capabilities, 4) Organizational abilities

Sedangkan variable kinerja diukur dengan Kaplan dan Norton (2001), bahwa Balance scorecard menyediakan framework untuk melihat dari segi strategi untuk menciptakan value dari 4 perspektif yang berbeda :

1. financial : strategi untuk pertumbuhan, profitability, dan resiko dilihat dari kacamata stakeholder

2. costumer: strategi untuk menciptakan value dan perbedaan dari perspective pelanggan.

3. Internal Business Process : prioritas strategi untuk bermacam proses bisnis, dimana untuk menciptakan kepuasan pada pelanggan dan stakeholder.

4. Learning and Growth : prioritas untuk mencipatakan keadaan yang mendukung perubahan organisasi, inovasi dan pertumbuhan.

\section{METODE}

Sampel yang digunakan dalam penelitian ini adalah 187 sampel. Hipotesis tersebut di atas akan diuji menggunakan teknis analisis structural equation modeling (SEM) karena hipotesis tersebut menunjukkan hubungan kausalitas antar dua buah variabel laten. Dalam hal ini perubahan organisasi exogenous latent variable diukur oleh dimensi 1) Human resources, 2) Functional resources, 3) Technological capabilities, 4) Organizational abilities dan kinerja PDAM sebagai endegenous latent variable diukur oleh dimensi financial, costumer, internal process, learning and growth. Proses structural equation modeling (SEM) menggunakan metode Maximum Likelihood Estimation (MLE), sedangkan pengujian kecocokan model dilakukan melalui pengujian secara inferensial yaitu chi-square dan secara deskriptif menggunakan beberapa ukuran Goodness of Fit (GOF). Diperoleh hasil chi-square 22.968 dengan nilai $p$-value 0.635 , Root Mean Square Error of Approximation $($ RMSEA $)=0.000$, Goodness of Fit Index $(G F I)=$ 0.963 , yang menunjukkan bahwa model fit. Dengan demikian dapat disimpulkan bahwa secara keseluruhan model diterima.

Pengujian terkait pada hipotesis penelitian adanya pengaruh perubahan organisasi terhadap kinerja Perusahaan Daerah Air Minum Kota Bandung diperoleh hasil sebagai berikut :

Tabel 1. Pengujian Hipotesis Penelitian

\begin{tabular}{ccccc}
\hline Pengaruh & Koefisien Jalur & t-hitung & t-tabel & Keterangan \\
\hline$\xi_{1} \rightarrow \eta_{1}$ & 0.97 & 8.85 & 1.978 & $\begin{array}{c}\text { Terdapat } \\
\text { pengaruh yang }\end{array}$ \\
\hline
\end{tabular}


Sumber : Hasil data yang diolah, 2010-2011

\section{HASIL DAN PEMBAHASAN}

Perubahan organisasi yang dilakukan pada PDAM Kota Bandung secara formal adalah mengubah SOTK PDAM yang ditetapkan berdasarkan Surat Keputusan Walikotamadya Daerah Tingkat II Bandung No. 2072 Tahun 1988 tentang Susuan Organisasi dan Tata Kerja PDAM Kotamadya Dati II Bandung yang memperlihatkan penempatan posisi-posisi struktur jabatan dan pemilahan bagian atau sub bagian dari masing-masing struktur yang tidak konsisten dan tidak lazim. Oleh karena itu perubahan organisasi yang dilakukan pada PDAM Kota Bandung mengubah: (1) Struktur Unit Pengamanan yang sebelumnya berada di posisi Technostructure, menjadi ditempatkan (atau menjadi bagian dari) posisi Supportingstaf. (2) Dengan adanya pergeseran paradigma organisasi terkait dengan organizational knowledge creation menurut Ulrich Dave, berarti kemampuan perusahaan secara keseluruhan menciptakan pengetahuan baru, produk, service, dan sistem, maka Unit Penelitian dan Pengembangan perlu mendapatkan perluasan fungsi, yang sebelumnya unit fungsi tersebut hanya terbatas dimana Tupoksinya belum terdefinisi dengan jelas atau spesifik (uraian kerja tidak jelas), dengan perubahan organisasi PDAM Kota Bandung diubah sehingga unit ini juga menambah fungsi general planing/startegic planing termasuk juga fungsi monitoring dan evaluasi. Nomenklatur Unit Penelitian dan Pengembangan pada posisi Technostructure memiliki arti yang lebih luas dari cakupan fungsi yang dilaksanakan yaitu menyusun, mengembangkan dan mengendalikan program PDAM oleh karena itu nomenklatur dan fungsi unit ini dirubah dengan sebutan Satuan Pengembangan dan Pemantauan Program (SP3). (3) Pemilahan unit kerja pada Direktur Umum yang sebelumnya tidak lazim. Hal ini terlihat adanya Bagian Pembukuan yang sejajar dengan Bagian Keuangan. Lazimnya Bagian Pembukuan merupakan unit kerja atau menjadi bagian dari Keuangan. Oleh karena itu bagian pembukuan dengan perubahan organisasi PDAM Kota Bandung diubah sehingga ditempatkan pada posisi di bawah atau menjadi salah satu bagian dari Bagian Keuangan. (4) Bagian Personalia yang sebelumnya menjadi bersatu dengan Tata Usaha. Kedua unit kerja ini merupakan kegiatan yang terpisah. Apalagi sebagai sebuah perusahaan sebesar PDAM, bagian personalia memerlukan unit kerja khusus yang terpisah dengan bagian-bagian yang lain. Demikian juga dengan sebutan Personalia yang hanya ruang lingkup terbatas pada masalah-masalah kepegawaian, menjadi terlalu sempit apalagi bila ingin dikembangkan ke lingkup yang lebih luas pengembangan pegawai. Oleh karena itu dengan perubahan organisasi PDAM Kota Bandung diubah sehingga sebutan yang lazim unit kerja yang mengelola kepegawaian dan pengembangannya adalah bagian Sumber Daya Manusia.

Penulis melihat bahwa perubahan organisasi PDAM Kota Bandung saat ini sangat mempertimbangkan segala peluang dan keterbatasan yang ada, terutama dari aspek regulasi payung hukum yang lebih tinggi. lingkup organisasi PDAM menurut structure in five dari Mintzberg menunjukkan hal yang relatif sedang. 
Mintzberg menyatakan bahwa setiap organisasi mempunyai lima bagian dasar yang didefinisikan sebagai berikut: (1) The operating core. Para pegawai yang melaksanakan pekerjaan dasar yang berhubungan dengan produksi, dalam hal ini kepala seksi atau kepala sub bagian besreta bawahannya. (2) The Strategic Apex. Manajer tingkat puncak yang diberi tanggung jawab keseluruhan untuk organisasi itu, dalam hal ini direksi PDAM. (3) The Middle line. Para manajer yang menjadi penghubung operating core dengan strategic apex, dalam hal ini para Kepala Bagian. (4) The Technostructure. Para analis yang mempuyai tanggung jawab untuk melaksanakan bentuk standarisasi tertentu dalam organisasi, dalam hal ini adalah Staf Ahli, Unit Litbang dan Unit Pengawasan. (5) The support staff. Orangorang yang mengisi unit staf yang memberi jasa pendukung tidak langsung kepada organisasi, dalam hal ini adalah sekretariat perusahaan.

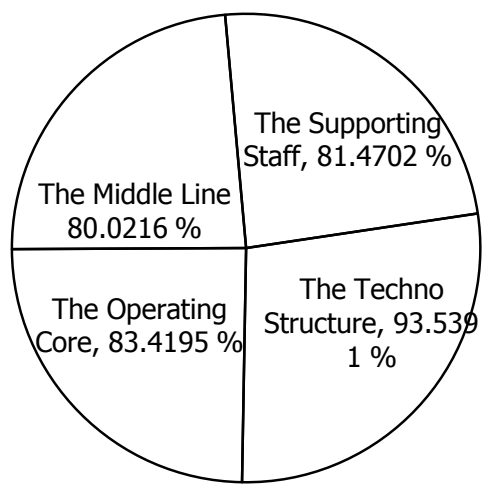

Gambar 1. Bagian Proporsi Perubahan Organisasi PDAM yang Mempengaruhi Kinerja PDAM Kota Bandung Dilihat Dari Perspektif Elemen Dasar Organisasi

Dari gambar di atas menunjukkan bahwa the technostructure merupakan elemen yang paling tinggi kinerjanya setelah dilaksanakan perubahan organisasi, disusul oleh operating core. Sedangkan para middle line merupakan elemen yang paling rendah kinerjanya dibanding level yang lain. Berdasarkan hasil wawancara kondisi ini terjadi karena middle line adalah jembatan antara strategic apex dengan operating core, sehingga selain harus menjalankan tugas dan fungsinya, elemen ini harus mampu menyampaikan kebijakan-kebijakan maupun nilai-nilai baru dari strategic apex kepada operating core. Apabila human relation atau sosialisasi dari level ini kurang baik maka akan banyak menuai protes dari operating core dan tekanan dari strategic apex. Jadi walaupun pelatihan setelah perubahan organisasi telah cukup baik dilakukan tetapi analisis jabatan belum dilakukan sehingga penempatan pegawai pada level tertentu menjadi kurang optimal. 


\section{SIMPULAN}

Pengaruh perubahan organisasi terhadap kinerja Perusahaan Daerah Air Minum Kota Bandung sangat tinggi, artinya perubahan organisasi dipandang sebagian besar responden memberikan kontribusi yang signifikan terhadap peningkatan kinerja Perusahaan. Dimensi terbesar memberi kontribusi pada perubahan organisasi PDAM adalah functional resources dan yang terkecil adalah technological capabilities. Sedangkan dimensi terbesar memberi kontribusi pada variabel kinerja PDAM adalah learning and growth, dan yang terkecil adalah financial

Dimensi functional resources menunjukkan bahwa belum optimalnya sosialisasi budaya kerja yang baru, belum seluruh pegawai mentaati norma organisasi yang baru, adanya orientasi kekuasaan yang sangat kuat untuk mendapatkan dan mempertahankan jabatan yang terlihat dari sikap dan prilaku pimpinan pada level middle ke atas. Selain itu perubahan perilaku pegawai PDAM Kota Bandung sebenarnya belum menunjukkan perubahan ke arah yang lebih baik. hal ini dapat dipahami mengingat mengubah perilaku pegawai lebih sulit ketimbang mengubah struktur organisasi.

Selain kondisi diatas, besarnya pengaruh perubahan organisasi terhadap kinerja Perusahaan Daerah Air Minum Kota Bandung sangat tinggi terlihat pada The Tecnostructure dan Operating Core. Para analis yaitu staf ahli, litbang dan unit pengawasan serta para pegawai yang melaksanakan pekerjaan dasar yang berhubungan dengan produksi kinerjanya lebih meningkat dibandingkan level The Middle line keatas

Dalam upaya mengembangkan teori perubahan organisasi disarankan lagi bagi penelitian yang lain agar meneliti secara mendalam tentang organizational behaviour termasuk didalamnya perilaku individu dalam organisasi. Analisis jabatan pun harus menjadi kajian penting dalam perubahan organisasi dalam menempatkan pegawai dalam tiap level/elemen dasar organisasi, karena hal tersebut diindikasikan mempunyai pengaruh yang kuat terhadap kinerja organisasi secara keseluruhan dan diharapkan dapat ditemukan konsep-konsep baru lagi mengenai perubahan organisasi, bagaimana cara yang terbaik agar perubahan yang dilakukan dapat diterima oleh seluruh tingkatan dalam organisasi. Selain itu disarankan pula kepada peneliti lain untuk meneliti perubahan organisasi menggunakan metode kualitatif, sehingga peneliti dapat mempelajari lebih mendalam.

PDAM disarankan untuk lebih memperhatikan jenjang karier yaitu proses penempatan pegawai sesuai kompetensi, terutama pada level middle line karena kondisi tersebut berpengaruh terhadap orientasi pada setiap unit kerja, kemampuan produksi dan modifikasi produk serta pelayanan terhadap pelanggan. 


\section{DAFTAR PUSTAKA}

Jones, Garet R. 1995. Organizational Theory: Text and Cases. Boston USA : Addison-Wesley Publishing Company, Inc.

Kaplan, R.S. and Norton, D.P 1992. Balance Scorecard-measures that drive performace. Boston, MA : Harvard Business Scholl Press.

Mintzberg, Henry. 1979. Organization Power and Goals in Charles Hofer and Dan Schedel, Strategic Management: A New View of Business Policy and Planning. Boston : Little Brown.

. 1983. Structure in Five : Designing Effective Organization, Englewood Cliffs, New Jersey : Printice Hall International Inc.

Winardi, J. 2003. Teori Organisasi dan Pengorganisasian. Jakarta : PT. Raja Grafindo Persada.

Winardi, J. 2005. Pemikiran Sistemik dalam Bidang Organisasi dan Manajemen, Jakarta : PT. Raja Grafindo Persada. 